\title{
K-10 montmorillonite: An efficient and reusable catalyst for selective oxidation of aldehydes in the presence of dioxygen
}

\author{
Ikram El Amrani *and Ahmed Atlamsani \\ University Abdelmalek Essaadi, Faculty of Sciences - Tetouan, Laboratory of Materials and Interfacial Systems, \\ PO Box 2121, 93030, Tetouan, Morocco
}

\begin{abstract}
A commercial montmorillonite clay catalyst, K-10 montmorillonite, was tested for catalytic oxidation of aldehydes in the presence of molecular oxygen under mild conditions. K-10 montmorillonite catalysed the oxidation of aldehydes with good activity and excellent selectivity toward the formation of the corresponding acids. The effects of the amount of catalyst, temperature and solvent on the catalytic activity were investigated. Remarkably, this catalyst was reusable without any appreciable loss in activity and selectivity.
\end{abstract}

Keywords: Aldehydes; Carboxylic acids; heterogeneous catalysts; Oxidation; Recycling.

\section{Introduction}

Selective catalytic oxidation of aldehydes to corresponding acids has recently been subject to considerable interest due to various potentials in organic synthesis and industrial applications ${ }^{1,2}$. In addition to numerous versatile methods for the oxidation of aldehydes, more convenient methods such as Baeyer-Villiger oxidation ${ }^{3-7}$, Cannizzaro reaction ${ }^{8-13}$, and metal catalysed oxidation have been reported ${ }^{14-19}$

Although many reagents are known to oxidize alcohols to aldehydes or ketones ${ }^{20,21}$, the next step of oxidation from the aldehyde to acid is relatively much more difficult to achieve using a very mild procedure and ensuing good yields ${ }^{22}$. Various oxidants such as $t$ - $\mathrm{BuOOH}{ }^{23}, \mathrm{H}_{2} \mathrm{O}_{2}{ }^{3,18,24}$, and molecular oxygen ${ }^{25-27}$ are applied in the catalytic oxidation of aldehydes to the corresponding carboxylic acids. However, despite the merits of these procedures, they might have various disadvantages such as harsh reaction conditions, the excessive requirement for reagents or catalysts, prolonged reaction time, tedious work-up procedures, non-reusability of the catalysts, and low yields of products. Development of a more efficient, convenient, and environment-friendly oxidation methods for aldehydes is therefore still a significant experimental challenge for chemists. The development of heterogeneous catalysts for the aerobic oxidation of organic compounds is a challenging goal ${ }^{28-33}$. Dioxygen and commercially available K-10 montmorillonite are materials that can fulfil these requirements. K-10 montmorillonite has been widely used in synthetic organic chemistry because it is a non-toxic, reusable, inexpensive,

*Corresponding author: Ikram El Amrani

Email address : elamra.ikram@gmail.com DOI: http://dx.doi.org/10.13171/mjc851907052iea preventing waste, and promote the atom economy. It is highly effective under mild reaction conditions, and recyclable purpose ${ }^{34-38}$. K-10 montmorillonite is a solid acid of moderate acid strength. Its Hammett constant is $\mathrm{H}_{0}=-8$, which is similar to that of concentrated $\mathrm{HNO}_{3}$. It is a layered alumino-silicate with a dioctahedral layer sandwiched between two tetrahedral layers ${ }^{39}$.

Clays function as efficient catalysts for various organic transformations due to their Brönsted and Lewis acidities in both their natural and ionexchanged forms ${ }^{40}$. Due to intense catalytic activity as Brönsted acid, K-10 montmorillonite clay has been used extensively as a catalyst in $\gamma$-lactones ${ }^{41}$. The synthesis of fused heterocycles ${ }^{42}$, the Friedel-Crafts reaction ${ }^{43}$, acetal and ketal deprotection reactions, selective bromination of alkylbenzenes ${ }^{44}$, oxidation of organic sulfides to sulfoxides ${ }^{45}$, the synthesis of biomarkers ${ }^{46}$, oxidative demethylation of methyl phenols to benzoquinones ${ }^{47},(2,5)$ intramolecular ene cyclization ${ }^{48}$, Michael addition ${ }^{49}$, Boc group removal from aromatic amines ${ }^{50}$, and the Diels-Alder reaction ${ }^{51}$.

In the present work, we set out to optimize conditions for the oxidation of aldehydes to carboxylic acids in the presence of dioxygen. Most experimental parameters, such as the amount of catalyst, temperature, and solvent were systematically optimized.

\section{Results and Discussion}

\section{Characterization of the materials}

Received April 25, 2019

Accepted May 31, 2019

Published July 5, 2019 
The composition (wt \%) of K-10MT determined by X-ray fluorescence (XRF) includes $82.67 \%$ of $\mathrm{SiO}_{2}$ , $13.93 \%$ of $\mathrm{Al}_{2} \mathrm{O}_{3}, 1.61 \%$ of $\mathrm{Fe}_{2} \mathrm{O}_{3}, 0.32 \%$ of $\mathrm{TiO}_{2}$, $0.10 \%$ of $\mathrm{CaO}$, and $1.36 \%$ of $\mathrm{K}_{2} \mathrm{O}$. The calculated cation exchange capacity was 0.8 mequiv./g clay.

The X-ray diffraction patterns of the K-10MT before (a) and after (b) oxidation reaction are presented in Figure 4. They exhibit characteristic reflections usually observed for smectites ${ }^{52}$. The basal spacing $\left(\begin{array}{lll}\mathrm{d}_{0} & 0 & 1\end{array}\right)$ for $\mathrm{K}-10 \mathrm{MT}$ is about $10.3^{\circ} \mathrm{A}$. The different $\left(\begin{array}{lll}0 & 0 & 1\end{array}\right)$ positions observed could, thus, be explained by different water amounts in the interlamellar space of the clay mineral. Moreover, the (lllll $\left.\begin{array}{lll}0 & 0 & 1\end{array}\right)$ peak is broader, which can be explained by considering a higher crystallization state of K-10MT.

Infrared spectra (Figure 5) are evident in the frequency range of $4000-400 \mathrm{~cm}^{-1}$. The distinct increase of infrared absorbency at $3620-918 \mathrm{~cm}^{-1}$ confirms the dominant presence of di-octahedral smectite with $[\mathrm{Al}, \mathrm{Al}-\mathrm{OH}]$ stretching and bending bands ${ }^{53}$. The adsorption bands at $3412-1645 \mathrm{~cm}^{-1}$ correspond to $\mathrm{OH}$ frequencies for the water molecule adsorbed on the clay surface. Bands at $468-520 \mathrm{~cm}^{-1}$ can be assigned to [Si-O-Al] and [Si-O-Si]. Bands at $806 \mathrm{~cm}^{-1}$ are characteristics of quartz. The (Si-O) bands are strongly evident in the structure and can be readily recognized in the infrared spectrum by the very strong adsorption bands in the $1100-1000 \mathrm{~cm}^{-1}$ region.

\section{Oxidation of hexanal}

The study of the oxidation of aldehydes uses commercial K-10MT as heterogeneous and dioxygen as a clean oxidant. Initially, the oxidation of hexanal was chosen in order to investigate the catalytic activity, selectivity, and stability of the clays.

\section{The amount effect of catalyst and substrate}

The amount effect of K-10MT on the conversion of hexanal, using a mixed water/acetic acid $(4.5 / 0.5 \mathrm{~mL} / \mathrm{mL})$ solvent was investigated (Figure 1). The amount of K-10MT was increased from 0 to 0.6 $\mathrm{g}$, and the conversion of the hexanal was increased to reach an optimum of $90 \%$ for $0.2 \mathrm{~g}$. This point can be explained by the increase in the number of acid and redox sites available for the oxidation reaction. Blank experiments performed in the absence of K-10MT showed that the hexanoic acid could not be synthesized.

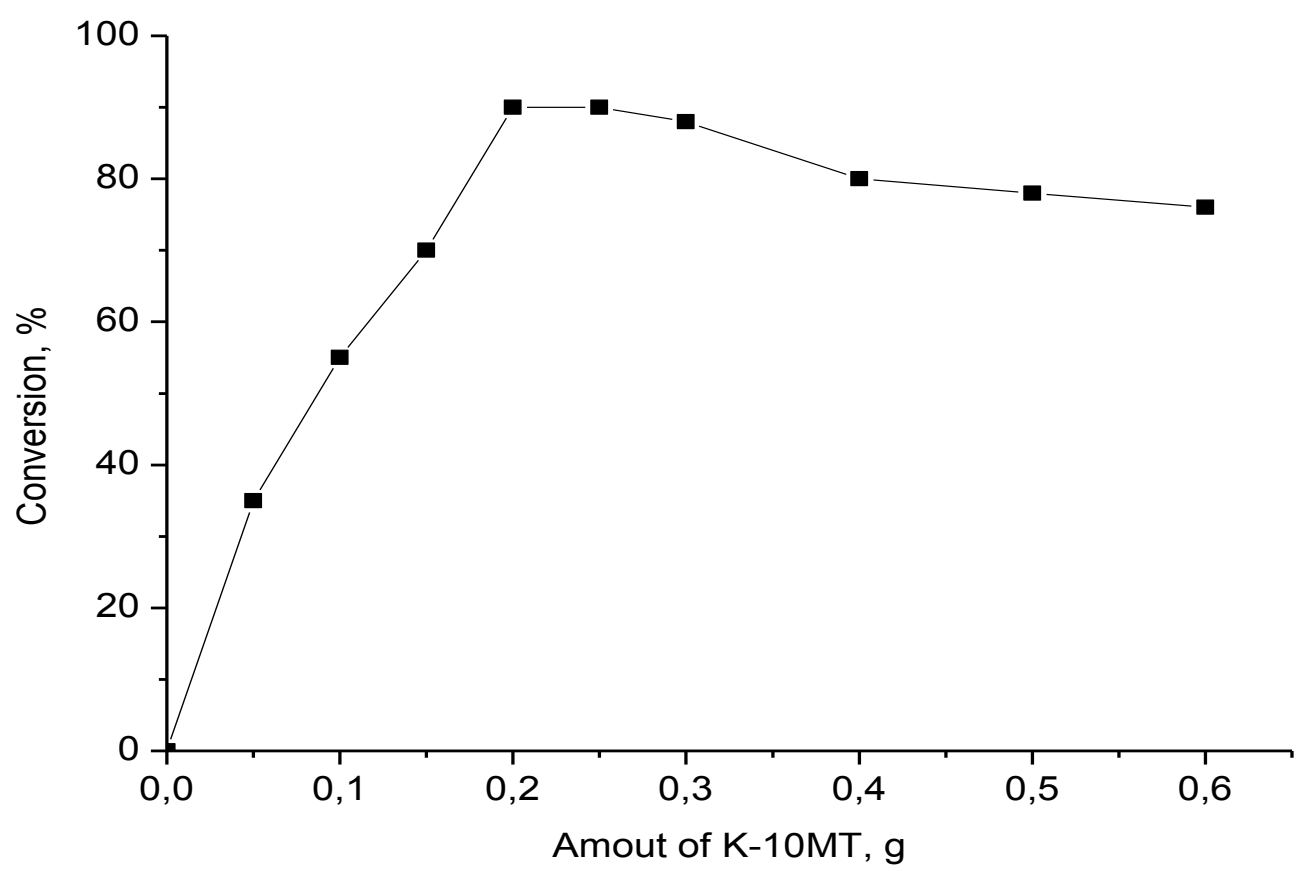

Figure 1. Effect of the catalyst amount on the conversion of hexanal.

Conditions: hexanal (5mmol), $\mathrm{AcOH} / \mathrm{H}_{2} \mathrm{O}(4.5 \mathrm{~mL} / 0.5 \mathrm{~mL}), \mathrm{H}_{3} \mathrm{PO}_{4}(0.2 \mathrm{mmol}), \mathrm{t}=24 \mathrm{~h}, \mathrm{~T}=70^{\circ} \mathrm{C}$, $\mathrm{p}\left(\mathrm{O}_{2}\right)=0.1 \mathrm{MPa}$.

The effect of the initial amount of hexanal (1-8 mmol, at $70^{\circ} \mathrm{C}$ ) was tested on the conversion rate by keeping the optimum amount of catalyst, which is $0.2 \mathrm{~g}$. As shown in Figure 2, the conversion increased with the increase in the quantity of hexanal reaching a maximum of $90 \%$ for $5 \mathrm{mmol}$. In the following, all the catalysis tests were; thus, performed using $0.2 \mathrm{~g}$ of solid K-10MT and $5 \mathrm{mmol}$ of the substrate as optimum values for maximum conversion. 


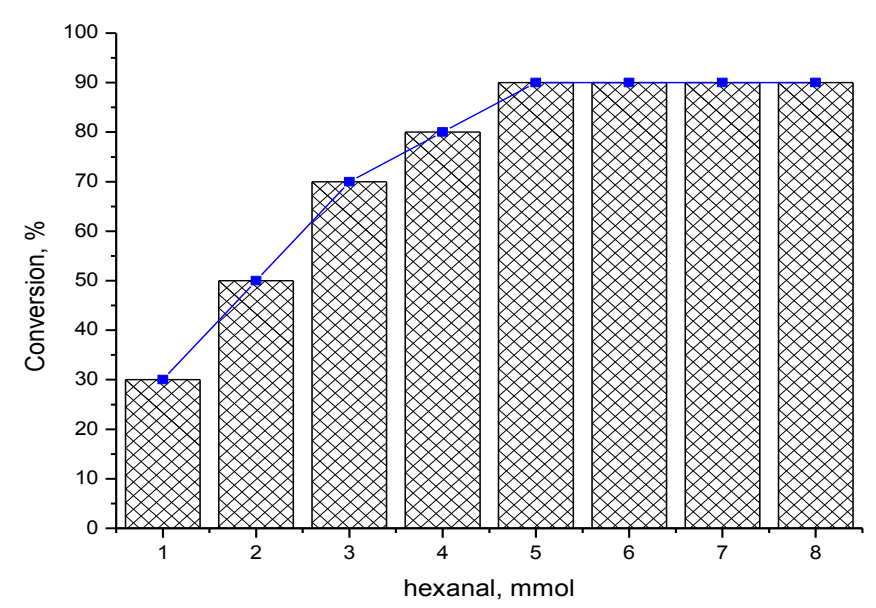

Figure 2. Effect of the substrate amount on the conversion of hexanal.

Conditions: K-10MT (0.2g), $\mathrm{H}_{3} \mathrm{PO}_{4}(0.2 \mathrm{mmol}), \mathrm{AcOH} / \mathrm{H}_{2} \mathrm{O}(4.5 \mathrm{~mL} / 0.5 \mathrm{~mL}), \mathrm{t}=24 \mathrm{~h}, \mathrm{~T}=70^{\circ} \mathrm{C}$, $\mathrm{p}\left(\mathrm{O}_{2}\right)=0.1 \mathrm{MPa}$.

\section{Effect of temperature}

We studied the temperature role on the conversion of hexanal into hexanoic acid. To this end, we realized the oxidation reaction at room temperature (Table 1, entry 1 ), at $40{ }^{\circ} \mathrm{C}$ (Table 1 , entry 2), and $70{ }^{\circ} \mathrm{C}$ (Table 1 , entry 3 ). The yield in acid was gradually increased from 16 to $88 \%$.

Table 1. Oxidation of hexanal with MT K-10/O ${ }_{2}{ }^{\mathrm{a}}$ : reaction temperature effect

\begin{tabular}{|c|c|c|c|c|}
\hline Entry & $\begin{array}{c}\text { Temperature } \\
\left({ }^{\circ} \mathbf{C}\right)\end{array}$ & $\begin{array}{c}\text { Time } \\
(\mathbf{h})\end{array}$ & $\begin{array}{c}\text { Conversion } \\
(\mathbf{\%})\end{array}$ & $\begin{array}{c}\text { Acid Yield }^{\mathbf{b}} \\
(\mathbf{\%})\end{array}$ \\
\hline $\mathbf{1}$ & r.t. & 48 & 16 & 14 \\
\hline $\mathbf{2}$ & 40 & 24 & 60 & 58 \\
\hline $\mathbf{3}$ & 70 & 24 & 90 & 88 \\
\hline
\end{tabular}

${ }^{\mathrm{a}}$ Conditions: hexanal (5mmol), K-10MT (0.2g), $\mathrm{H}_{3} \mathrm{PO}_{4}(0.2 \mathrm{mmol}), \mathrm{AcOH} / \mathrm{H}_{2} \mathrm{O}(4.5 \mathrm{~mL} / 0.5 \mathrm{~mL}), \mathrm{p}\left(\mathrm{O}_{2}\right)=0.1 \mathrm{MPa}$.

${ }^{\mathrm{b}}$ Conversions and yields were determined by $\mathrm{GC}$ analysis, ${ }^{\text {r.t. }}$. room temperature.

However, the optimal yield $(88 \%)$ was obtained after 24 hours of reaction at $70^{\circ} \mathrm{C}$ (Table 1 , entry 3 ). It should be noted that the $\mathrm{K}-10 \mathrm{MT}$ remains less active at room temperature (Table 1 , entry 1 ).

\section{Effect of solvent}

A solvent effect on the oxidation of hexanal with pure dioxygen and K-10MT was studied thoroughly. The main results obtained are summarized in Table 2.

Table 2. Effect of solvents on the catalytic oxidation of hexanal using (K-10MT) as a catalyst $\mathrm{t}^{\mathrm{a}}$

\begin{tabular}{|c|c|c|c|c|}
\hline Entry & Solvent $(\mathbf{m L})$ & $\mathbf{T}\left({ }^{\mathbf{C}} \mathbf{C}\right.$ & Conversion $^{\mathbf{b}}(\mathbf{\%})$ & Yield $^{\mathbf{b}}(\mathbf{\%})$ \\
\hline $\mathbf{1}$ & Toluene $(5)$ & 70 & 88 & 86 \\
\hline $\mathbf{2}$ & $\mathrm{THF}(5)$ & 40 & 90 & 87 \\
\hline $\mathbf{3}$ & $\mathrm{CH}_{3} \mathrm{CN}(5)$ & 70 & 88 & 86 \\
\hline $\mathbf{4}^{\mathbf{c}}$ & $\mathrm{MeOH}(5)$ & 60 & 13 & 12 \\
\hline $\mathbf{5}$ & - & 70 & 80 & 75 \\
\hline $\mathbf{6}$ & $\mathrm{H}_{2} \mathrm{O}(5)$ & 70 & 45 & 64 \\
\hline $\mathbf{7}$ & $\mathrm{AcOH}(5)$ & 70 & 70 & 88 \\
\hline $\mathbf{8}$ & $\mathrm{AcOH} / \mathrm{H}_{2} \mathrm{O}(4.5 / 0.5)$ & 70 & 90 & 43 \\
\hline $\mathbf{9}$ & $\mathrm{AcOH} / \mathrm{H}_{2} \mathrm{O}(4 / 1)$ & 70 & 45 & 42 \\
\hline $\mathbf{1 0}$ & $\mathrm{AcOH} / \mathrm{H}_{2} \mathrm{O}(3 / 2)$ & 70 & 43 & 37 \\
\hline
\end{tabular}

${ }^{\mathrm{a}}$ Conditions: hexanal $(5 \mathrm{mmol}), \mathrm{K}-10 \mathrm{MT}(0.2 \mathrm{~g}), \mathrm{H}_{3} \mathrm{PO}_{4}(0.2 \mathrm{mmol}), \mathrm{t}=24 \mathrm{~h}, \mathrm{~T}=70^{\circ} \mathrm{C}, \mathrm{p}\left(\mathrm{O}_{2}\right)=0.1 \mathrm{MPa}$.

${ }^{\mathrm{b}}$ Conversions and yields were determined by GC analysis.

${ }^{c}$ Twenty-four hour, the product is identified as methyl heptanoate. 
We have tested many solvents with different properties (non-polar, polar protic, and polar aprotic), in order to find the best media of our oxidation. Thus, moderate conversions and yields are observed using Toluene, THF, $\mathrm{CH}_{3} \mathrm{CN}$, and $\mathrm{MeOH}$ (Table 2, entries 1-4). In the absence of a solvent (Table 2, entry 5) complete conversion was obtained without a considerable reduction in the yield of the reaction, which was around $80 \%$. In aqueous media, the conversion reaches only $45 \%$ after 24 hours of reaction time (Table 2, entry 6 ) and with pure acetic acid $(\mathrm{AcOH})$; slightly lower values are obtained in (Table 2, entry 7). The best result is obtained with $\mathrm{AcOH} / \mathrm{H}_{2} \mathrm{O}(4.5 \mathrm{~mL} / 0.5 \mathrm{~mL})$, giving $90 \%$ conversion after $24 \mathrm{~h}$ (Table 2, entry 8). Probably, this mixture provides good acidity for the medium of reaction that promotes the oxidation of the hexanal.

Even if the initial rates are higher for compositions with a lower $\mathrm{AcOH} / \mathrm{H}_{2} \mathrm{O}$ ratio (4/1, 3/2, or 2.5/2.5 (v/v)), see (Table 2, entries 9-11), the final conversions after $24 \mathrm{~h}$ drop dramatically to values less than half of those obtained with $\mathrm{AcOH} / \mathrm{H}_{2} \mathrm{O}$.

Moreover, X-ray fluorescence analyses have shown that iron and titanium are present in K-10MT.

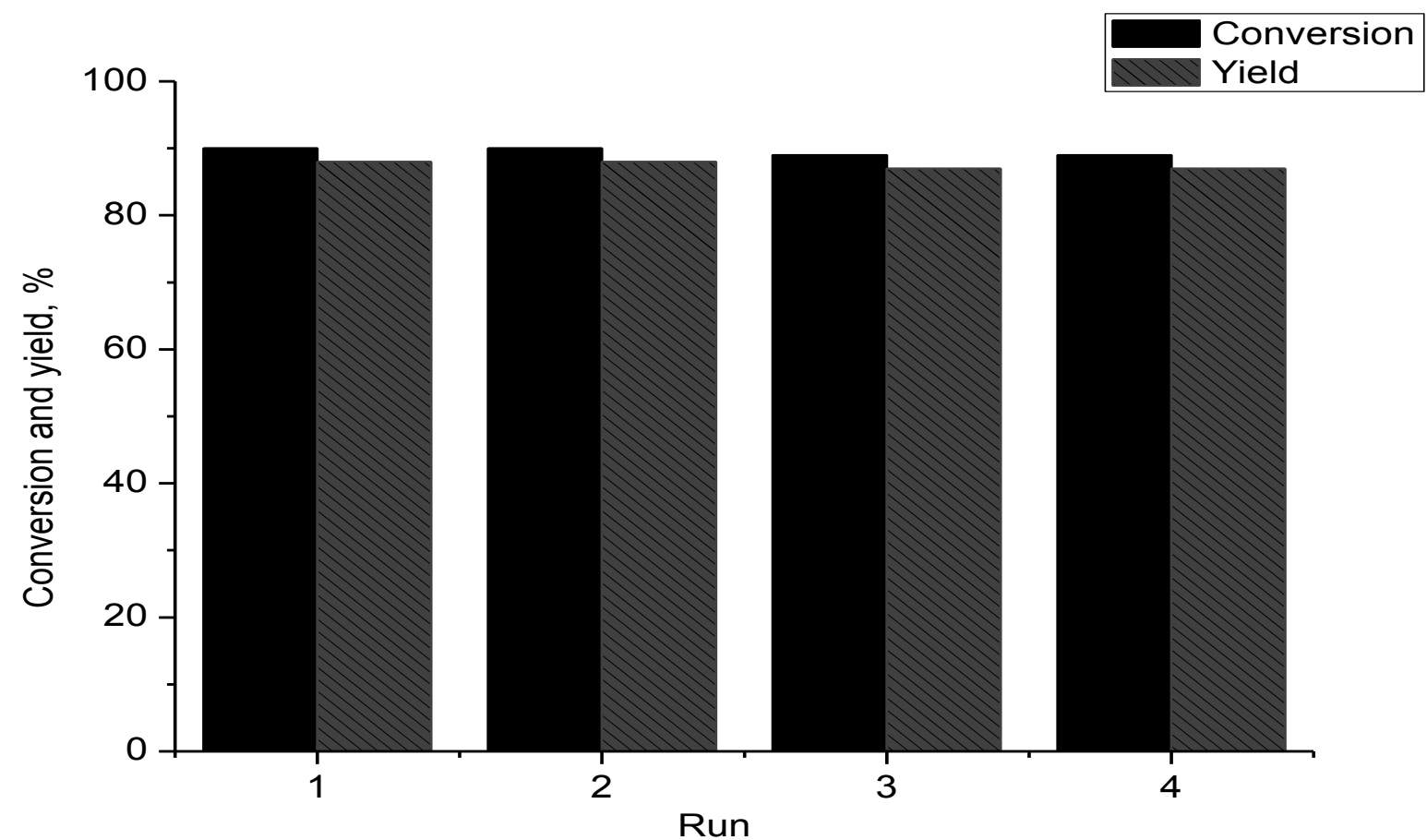

Figure 3. Recycling of K-10MTcatalyst in the oxidation of hexanal by dioxygen.

Conditions: hexanal (5mmol), K-10MT (0.2g), $\mathrm{H}_{3} \mathrm{PO}_{4}(0.2 \mathrm{mmol}), \mathrm{AcOH} / \mathrm{H}_{2} \mathrm{O}(4.5 \mathrm{~mL} / 0.5 \mathrm{~mL}), \mathrm{t}=24 \mathrm{~h}$, $\mathrm{T}=70^{\circ} \mathrm{C}, \mathrm{p}\left(\mathrm{O}_{2}\right)=0.1 \mathrm{MPa}$

We would like to emphasize that the crystallographic structure of the K-10MT was not altered through the experiments. Thus, the X-ray
Thus, the active species could correspond to $\mathrm{Fe}(\mathrm{II})$ and/or Fe(III) species and/or Ti(IV). We think that the mixed solvent $\mathrm{AcOH} / \mathrm{H}_{2} \mathrm{O}(4.5 \mathrm{~mL} / 0.5 \mathrm{~mL})$ facilitates the reduction rate of $\mathrm{M}^{\mathrm{n}+}(\mathrm{M}=\mathrm{Fe}$ or $\mathrm{Ti})$ and increases the solubility of dioxygen ${ }^{54}$. In the following, the tests have been carried out with the $\mathrm{AcOH} / \mathrm{H}_{2} \mathrm{O}=4.5 / 0.5$ (v/v) mixed solvent.

\section{Catalyst regeneration}

The K-10MT obtained was separated at the reaction temperature from the reaction mixture by filtration and washed four times with distilled water. The resulting K-10MT was dried at $373 \mathrm{~K}$ for $10 \mathrm{~h}$, grounded into a fine powder and used again to study its activity for the oxidation reaction. Figure 3 shows that the K-10MT can be recycled several times without any significant loss in activity and selectivity (the small observed variations are within the experimental error). This means that the structure of the active centers is maintained from one test to another. Structural evolution of recovered catalyst at the end of the reaction was monitored with X-ray diffraction (Figure 4) and IR spectra (Figure 5) and XRF Table 3. 


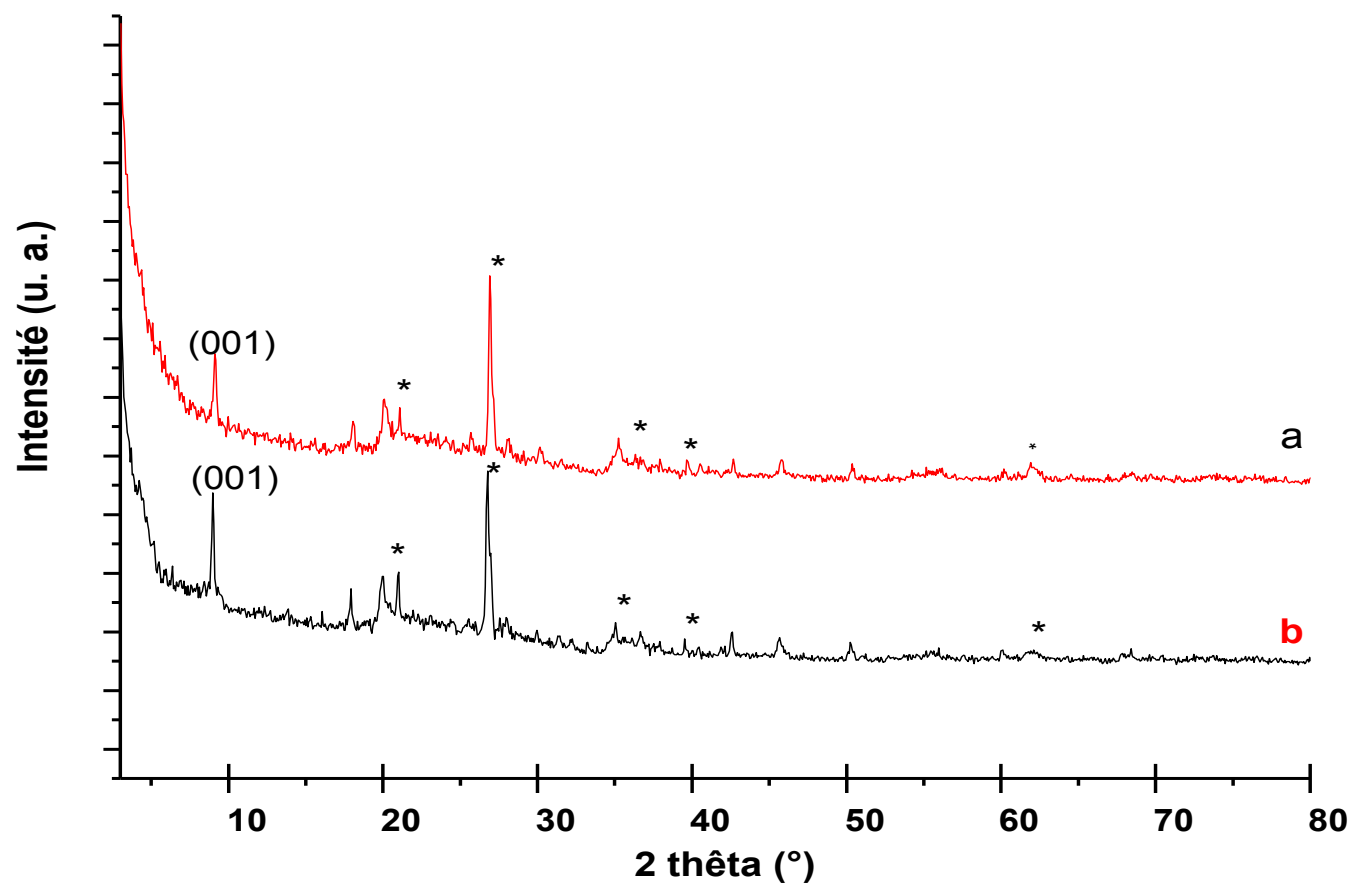

Figure 4. X-ray diffractograms of K-10MT before (a) and after (b) oxidation reaction.

*: quartz

The IR spectra of K-10MT after oxidation reaction show the characteristic bands of
$\mathrm{K}-10 \mathrm{MT}$, which correspond to $\mathrm{Si}-\mathrm{O}$ and $\mathrm{Al}-\mathrm{OH}$ (Figure 5).

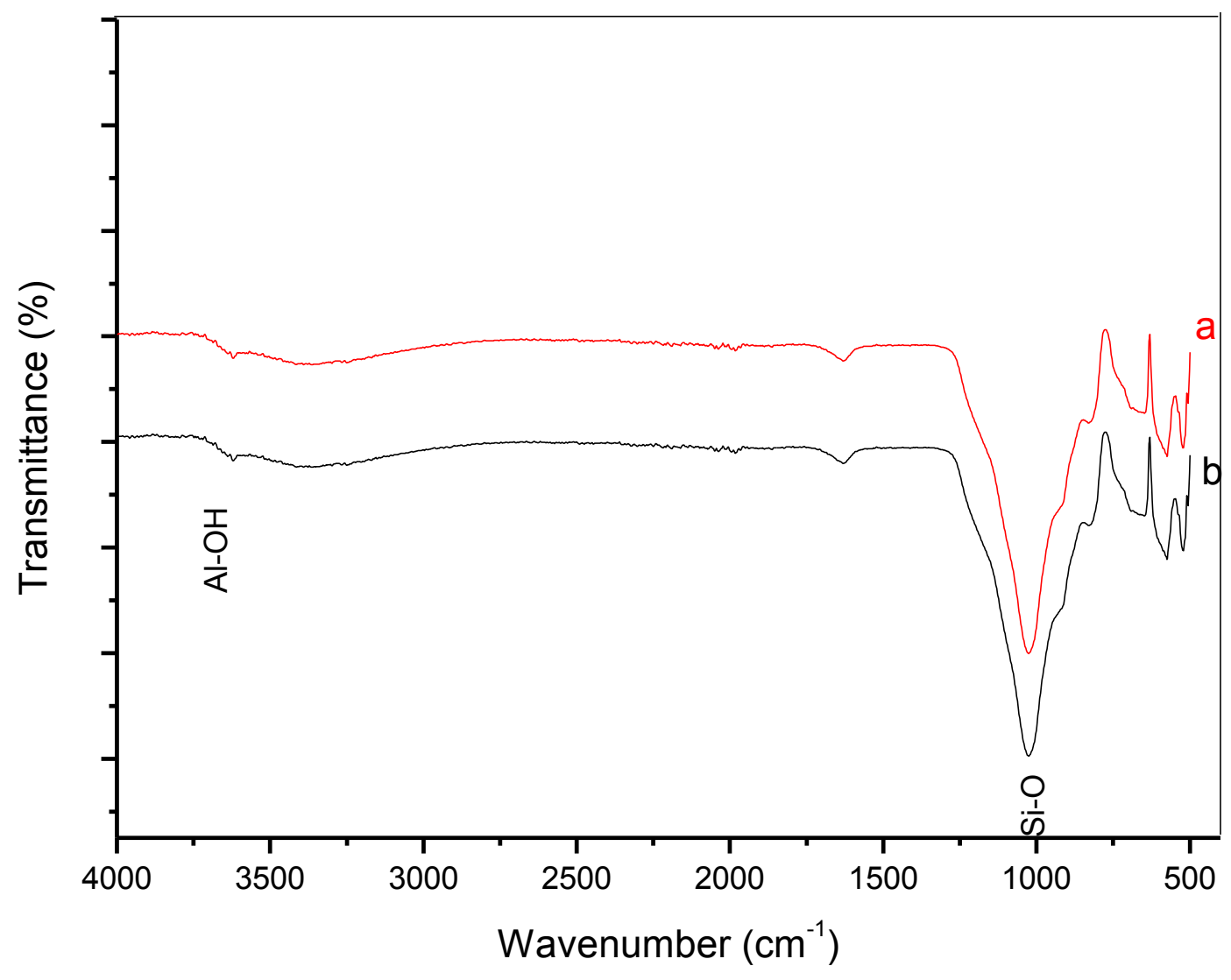

Figure 5. IR spectra of K-10MT before (a) and after (b) oxidation reaction. 
Table 3. X-ray fluorescence analyses of the fresh and recovered catalysts.

\begin{tabular}{|c|c|c|c|c|c|c|}
\hline \multirow{2}{*}{ Run } & \multicolumn{7}{|c|}{$\%(\mathbf{W} / \mathbf{W})$} \\
\cline { 2 - 7 } & $\mathrm{SiO}_{2}$ & $\mathrm{Al}_{2} \mathrm{O}_{3}$ & $\mathrm{Fe}_{2} \mathrm{O}_{3}$ & $\mathrm{TiO}_{2}$ & $\mathrm{CaO}$ & $\mathrm{K}_{2} \mathrm{O}$ \\
\hline $\mathbf{0}$ & 82,67 & 13,93 & 1,61 & 0,32 & 0,10 & 1,36 \\
\hline $\mathbf{1}$ & 82,72 & 13,93 & 1,52 & 0,34 & 0,09 & 1,40 \\
\hline $\mathbf{2}$ & 82,74 & 13,93 & 1,51 & 0,34 & 0,08 & 1,40 \\
\hline $\mathbf{4}$ & 82,75 & 13,93 & 1,50 & 0,34 & 0,08 & 1,40 \\
\hline $\mathbf{5}$ & 82,77 & 13,93 & 1,48 & 0,34 & 0,08 & 1,40 \\
\hline
\end{tabular}

Conditions: hexanal (5 mmol), K-10MT (0.2 g), $\mathrm{H}_{3} \mathrm{PO}_{4}(0.2 \mathrm{mmol}), \mathrm{AcOH} / \mathrm{H}_{2} \mathrm{O}(4.5 \mathrm{~mL} / 0.5 \mathrm{~mL}), \mathrm{t}=24 \mathrm{~h}$, $\mathrm{T}=70^{\circ} \mathrm{C}, \mathrm{p}\left(\mathrm{O}_{2}\right)=0.1 \mathrm{MPa}$.

The variations of the relative content of metals $\left(\mathrm{M} / \mathrm{M}_{0}\right)$ in the K-10MT with several runs are given in (Figure 6) in which $\mathrm{M}_{0}$ and $\mathrm{M}$ are the wt. \% of the oxide elements in the fresh clay and recovered catalysts samples. Different behaviours are observed depending on the nature of the element. The relevant contents of the leached elements in the K-10MT decrease in the order of $\mathrm{Ca}^{2+}, \mathrm{Fe}^{3+}, \mathrm{K}^{+}$, and $\mathrm{Ti}^{4+}$ with the increase in several runs.

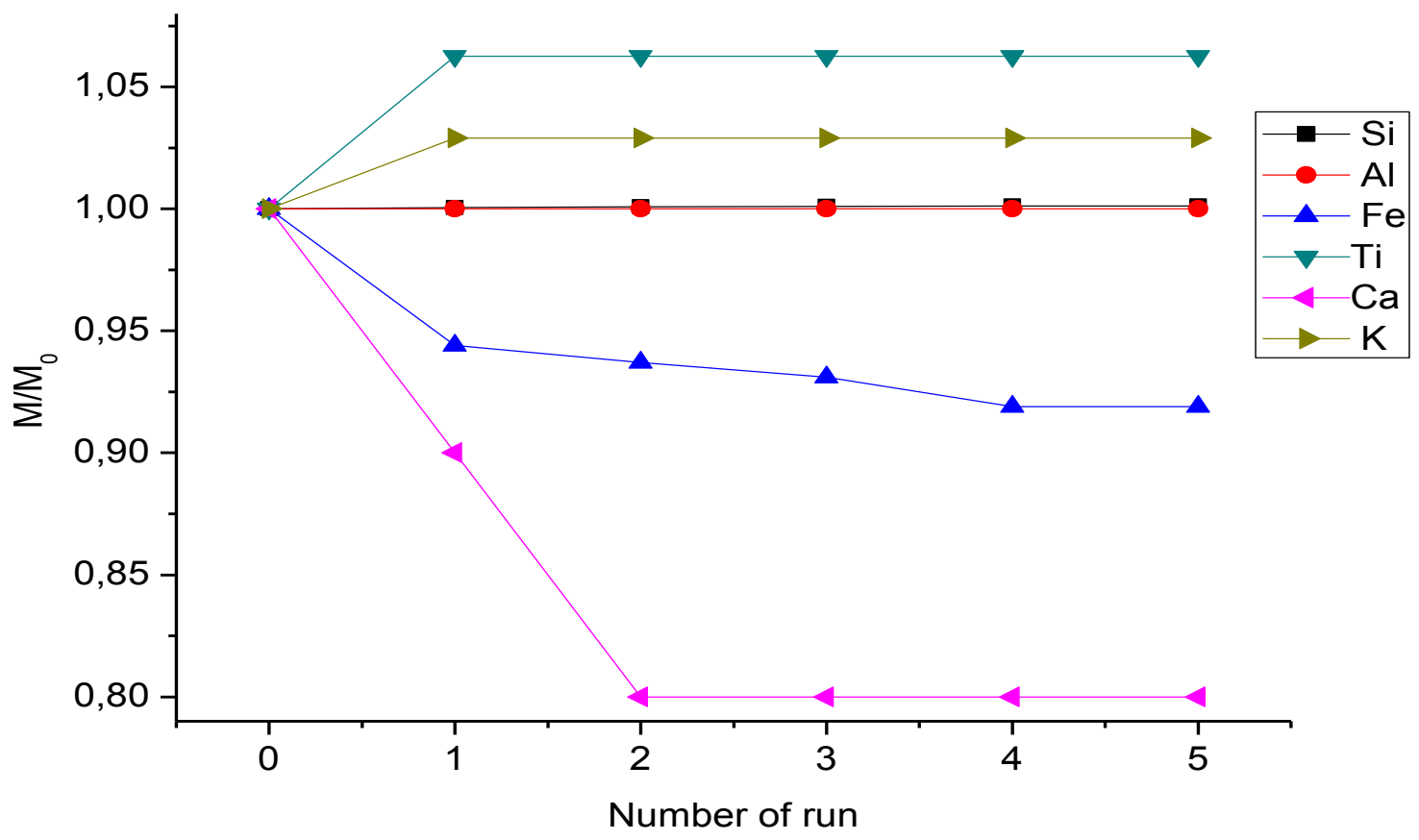

Figure 6. Variations of the relevant metal contents $\left(\mathrm{M} / \mathrm{M}_{0}\right)$ determined by XRF for K-10MT powder vs. the number of runs.

There is a marked decrease in the Ca element and, to a lesser extent, in the Fe. There is partial leaching of iron under the reacting conditions for the first four tests. After four tests, their amount in the solid material is nearly constant.

\section{Oxidation of other aldehydes}

The catalytic system (K-10MT/dioxygen/acetic acid/water) shows high catalytic activity for the oxidation of other aldehydes (Table 4). No oxidation products were detected in the absence of the $\mathrm{K}-$ 10MT catalyst.

Table 4. Oxidation of aldehydes to carboxylic acids by K-10MT $/ \mathrm{O}_{2} / \mathrm{AcOH}-\mathrm{H}_{2} \mathrm{O}$ system ${ }^{\mathrm{a}}$ 
${ }^{\mathrm{a}}$ Conditions: aldehyde (5mmol), $\mathrm{K}-10 \mathrm{MT}(0.2 \mathrm{~g}), \mathrm{H}_{3} \mathrm{PO}_{4}(0.2 \mathrm{mmol}), \mathrm{AcOH} / \mathrm{H}_{2} \mathrm{O}(4.5 \mathrm{~mL} / 0.5 \mathrm{~mL}), \mathrm{t}=24 \mathrm{~h}, \mathrm{~T}=70^{\circ} \mathrm{C}$,

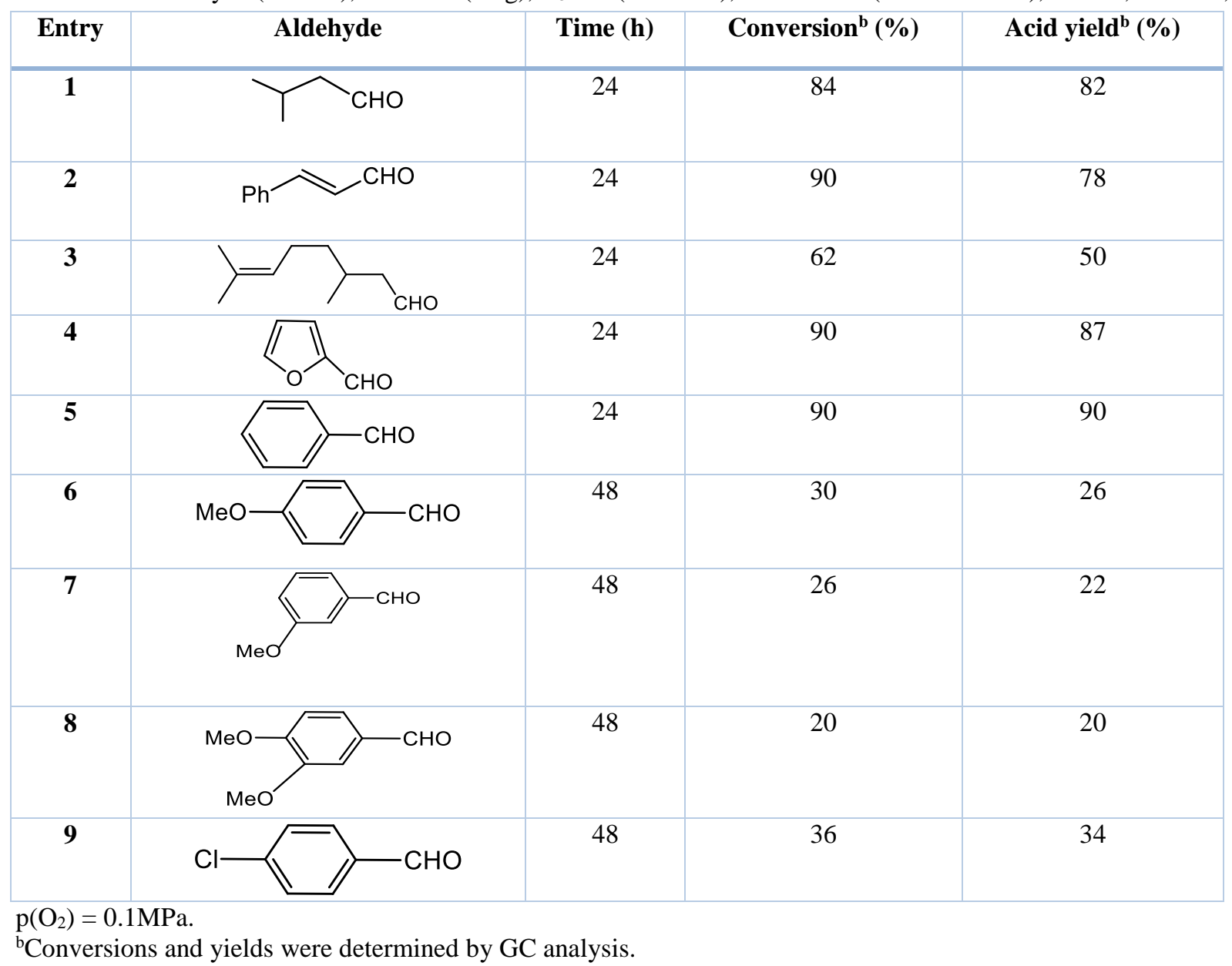

The oxidation of iso-valeraldehyde (Table 4, entry 1) provides iso-valeric acid as the main product. The oxidation of trans-cinnamaldehyde and citronellal were evaluated under the oxidative conditions of our catalytic system. These substrates contain aldehyde functionality together with an epoxidizable olefinic double bond ${ }^{27}$.

The results obtained show that the oxidation of trans-cinnamaldehyde (Table 4, entry 2) is selective towards the formation of trans-cinnamic acid (88\%). However, oxidative scission of the conjugated carbon-carbon double bond takes place in a lesser amount, resulting in the generation of side products. The oxidation of citronellal was also rather selective to the corresponding citronellic acid (Table 4, entry 3 ). Moreover, the treatment of furan-2carboxaldehyde produced furan-2-carboxylic acid in good yield (Table 4, entry 4).

In the last case, the reaction of benzaldehyde (Table 4, entry 5) provides benzoic acid in high yields, In contrast to the substitutions at a different position on the phenyl ring. The reaction is prolonged with substrates containing electron-donating substituents in the aromatic ring (Table 4, entries, 6- 9). These observations clearly show that such active electrondonating groups do not allow smooth oxidation of aldehydes to carboxylic acids because these types of aldehydes can also act as radical scavengers 27. Previous work ${ }^{55}$ showed that irons salts are efficient catalysts precursors for the oxidation of aldehydes. The X-ray fluorescence demonstrates that Fe cations were mainly located in the octahedral sheet K-10 montmorillonite ${ }^{56}$. There is partial leaching of iron under the reacting conditions. We; thus, could suspect the contribution of solvated iron species to the global catalytic activity. The active species could correspond to $\mathrm{Fe}$ (II) and /or Fe (III) intercalated between the clay layers and/or Ti (IV) species which are located in the tetrahedral sheet. To date, titanium (IV) has not been reported as a catalyst for such a reaction of aldehydes.

\section{Conclusion}

In this work, we have demonstrated that $\mathrm{K}-10 \mathrm{MT} / \mathrm{AcOH}-\mathrm{H}_{2} \mathrm{O} / \mathrm{O}_{2}$ catalytic system is an environmentally friendly process for the selective oxidation of aldehydes to carboxylic acids. The simple experimental and product isolation procedures, as well as the natural recovery and reuse of the catalyst, are expected to play an essential role in the development of this new method. Moreover, the conditions of these reactions might also represent a perfect alternative to the process carried out in the liquid phase, which is characterized by a no longer acceptable environmental impact. Further research 
will also develop toward elucidating the catalytic oxidation mechanism.

\section{Acknowledgements}

Ahmed Atlamsani and Ikram El Amrani would like to express their gratitude to the "Ministère de l'Enseignement Supérieur, de la Recherche scientifique et de la Formation des cadres" of Morocco for project PPR2.

\section{Experimental}

The K-10 montmorillonite (K-10MT) used in this work was purchased from Aldrich with a surface area $\left(\mathrm{S}_{\mathrm{BET}}\right)$ of $269 \mathrm{~m}^{2} \mathrm{~g}^{-1}$. All catalytic tests were carried out using Schlenk flasks $(20 \mathrm{~mL})$, which were attached to a vacuum line with a manometer and a gas inlet. In a typical experiment, the Schlenk (flasks) were filled with $5.0 \mathrm{~mL}$ of the corresponding solvent $\left(\mathrm{CH}_{3} \mathrm{CN}, \mathrm{H}_{2} \mathrm{O}, \mathrm{CH}_{3} \mathrm{OH}, \mathrm{CH}_{3} \mathrm{COOH}\right.$ or a mixture of $\mathrm{CH}_{3} \mathrm{COOH} / \mathrm{H}_{2} \mathrm{O}$ ) and $\mathrm{K}-10$ montmorillonite (K10MT) $(0.02 \mathrm{mmol})$. The substrate $(5.0 \mathrm{mmol})$ was then added, and the vessel was immersed in an oil bath preheated at $70{ }^{\circ} \mathrm{C}$. $\mathrm{O}_{2}$ was introduced at atmospheric pressure and the mixture was stirred magnetically for the time indicated in the tables. Three parallel catalytic experiments were carried out for each test. The addition of biphenyl as an internal standard at the end of the experiment permitted to quantitatively analyze the products using a Shimadzu GC-2010 gas chromatograph equipped with a Chiraldex G-TA column (30 m length $\times 25 \mathrm{~mm}$ diameter) and a flame ionization detector. Gas Chromatography conditions were as: initial temperature $60^{\circ} \mathrm{C}$ for $5 \mathrm{~min}$; ramp rate $10{ }^{\circ} \mathrm{C} \mathrm{min}^{-1}$; final temperature $170{ }^{\circ} \mathrm{C}$; injection temperature $250{ }^{\circ} \mathrm{C}$ (split mode); detector temperature $250{ }^{\circ} \mathrm{C}$ (detector FID); and carrier gas: mixture of helium, hydrogen, and air.

X-ray diffraction patterns were obtained with a Panalytical X'Pert Pro diffractometer equipped with an $\mathrm{X}^{\prime}$ Celerator detector using Fe-filtered $\mathrm{Co}-\mathrm{K}_{\alpha}$ radiation. The data were collected at room temperature with a $0.017^{\circ}$ step size in $2 \theta$ (scan step time $=25 \mathrm{~s}$ ), from $2 \theta=5$ to $110^{\circ}$. The crystalline phase was identified by comparison with ICSD reference files.

X-ray fluorescence analyses were carried out using a PANalytical MiniPal 4 spectrometer wavelength dispersion-type Axios.

Fourier transform infrared spectrometry analysis was carried out using a Varian 640-IR spectrometry in the region of 4000-400 $\mathrm{cm}^{-1}$. Samples were thoroughly mixed and ground with $\mathrm{KBr}$ powder to make a pellet for the Fourier transform infrared spectroscopy (FTIR) measurements.
1- X.T. Zhou, H. B. Ji, Q. L. Yuan, J. C. Xu, L. X Pei, L. F. Wang, Aerobic oxidation of benzylic aldehydes to acids catalyzed by iron (III) mesotetraphenylporphyrin chloride under ambient conditions, Chin. Chem. Lett., 2007, 18, 926-928.

2- F. F. Bamcharram, M. Roshani, M. H. Alizadeh, H. Razavi, M. Moghayadi, J. Brazil, Novel oxidation of aromatic aldehydes catalyzed by Preyssler's anion, $\left[\mathrm{NaP}_{5} \mathrm{~W}_{30} \mathrm{O}_{110}\right]^{14-}$, Chem. Soc., 2006, 17, 505-509.

3- R. Bernini, A. Coratti, G. Provenzano, G. Fabrizi, D. Tofani, Oxidation of aromatic aldehydes and ketones by $\mathrm{H}_{2} \mathrm{O}_{2} / \mathrm{CH}_{3} \mathrm{ReO}_{3}$ in ionic liquids: an efficient catalytic reaction to achieve dihydric phenols, Tetrahedron, 2005, 61, 1821-1825.

4- A. Corma, V. Fornés, S. Iborra, M. Mifsud, M. Renz, One-pot synthesis of phenols from aromatic aldehydes by Baeyer-Villiger oxidation with $\mathrm{H}_{2} \mathrm{O}_{2}$ using water-tolerant Lewis acids in molecular sieves, J. Catal., 2004, 221, 67-76.

5- H. Qian, L.-X. Shao, X. Huang, Polystyrenebound phenylseleninic acid: catalytic oxidation of aldehydes to carboxylic acids with hydrogen peroxide, J. Chem. Res-S., 2002, 514-515.

6- G. J. T. Brink, J. M. Vis, I.W.C. E. Arends, R. A. Sheldon, Selenium-Catalyzed Oxidations with Aqueous Hydrogen Peroxide. 2. BaeyerVilliger Reactions in Homogeneous Solution, J. Org. Chem., 2001, 66, 2429-2433.

7- K. Sato, M. Hyodo, J. Takagi, M. Aoki, R. Noyori, Hydrogen peroxide oxidation of aldehydes to carboxylic acids: an organic solvent-, halide and metal-free procedure, Tetrahedron. Lett., 2000, 41, 1439-1442.

8- K. H. Chung, B. C. Moon, C. H. Lim, J. P. Kim, J. H. Lee, D.Y. Chi, Oxidation of Aromatic Aldehydes with Tetrabutylammonium Fluoride: Competition with the Cannizzaro Reaction, Korean. Chem. Soc., 2006, 27, 1203-1205.

9- D. Basavaiah, D. S. Sharada, A.Veerendhar, Organo-base mediated Cannizzaro reaction, Tetrahedron. Lett., 2006, 47, 5771-5774.

10- M. S. Abaee, R. Sharifi, M. M. Mojtahedi, Room-Temperature Cannizzaro Reaction under Mild Conditions Facilitated by Magnesium Bromide Ethyl Etherate and Triethylamine, Org. Lett., 2005, 7, 5893-5895.

11- P. Appukkuttan, W. Dehaen, E. Van der Eycken, Transition-Metal-Free Sonogashira Type Coupling Reactions in Water, Eur. J. Org. Chem., 2003, 4713-4716.

12- M. Meciarova, V. Polackova, S. Toma, The Effect of Microwave and Ultrasonic Irradiation on the Reactivity of Benzaldehydes under

\section{References}


$\mathrm{Al}_{2} \mathrm{O}_{3}, \mathrm{Ba}(\mathrm{OH})_{2}$, and $\mathrm{K}_{2} \mathrm{CO}_{3}$ Catalysis, Chem. Pap., 2002, 56, 208-213.

13- B.V. S. Reddy, R. Srinivas, J. S. Yadav, T. Ramalingam, $\mathrm{KF}-\mathrm{Al}_{2} \mathrm{O}_{3}$ Mediated CrossCannizzaro Reaction Under Microwave Irradiation, Synth. Commun., 2002, 32, 219-223.

14- N. Barooah, S. Sharma, B. C. Sharma, J. B. Baruah, Catalytic oxidative reactions of organic compounds by nitrogen-containing copper complexes, Appl. Organometal. Chem., 2004, $18,440-445$.

15- T. Mallat, A. Baiker, Oxidation of Alcohols with Molecular Oxygen on Solid Catalysts, Chem. Rev., 2004, 104, 3037-3058.

16- A. N. Kharat, P. Pendleton, A. Badalyan, M. Abedini, M. M. Amini, Oxidation of aldehydes using silica-supported Co(II)substituted heteropolyacid, J. Mol. Catal. A: Chem., 2001, 175, 277-283.

17- A. Anjum, P. Srinivas, An Efficient and Mild Procedure for the Preparation of Benzoic Acids via Oxidation of Aromatic Carbonyl Compounds by Employing N-Bromoimides and Mercuric Acetate System, Chem. Lett., 2001, 30, 900-901.

18- M. Brzaszcz, K. Kloc, M. Maposah, J. Mlochowski, Selenium (IV) Oxide Catalyzed Oxidation of Aldehydes to Carboxylic Acids with Hydrogen Peroxide, Synth. Commun., 2000, 30, 4425-4434.

19- J. Howarth, Oxidation of aromatic aldehydes in the ionic liquid [bmim] $\mathrm{PF}_{6}$, Tetrahedron. Lett., 2000, 41, 6627-6629.

20- (a) S. Samajdar, F. F. Becker, B. K. Banik, Surface-Mediated Highly Efficient Oxidation of Alcohols By Bismuth Nitrate, Synth. Commun., 2006, 31, 2691-2695.

(b) M. Michela Dell'Annaa, M. Mali, P. Mastrorilli, P. Cotugnoc, A. Monopoli, Oxidation of benzyl alcohols to aldehydes and ketones under air in water using a polymersupported palladium catalyst, J. Mol. Catal. A: Chem., 2014; 386, 114-119.

21- J. Farkas, S. Bekassy, J. Madarasz, F. Figueras, Selective oxidation of benzylic alcohols to aldehydes with metal nitrate reagents catalyzed by BEA zeolites or clays, New J. Chem., 2002, 26, 750-754.

22- C. Mukhopadhyay, A. Datta, Bismuth(III) nitrate pentahydrate: a stoichiometric reagent for microwave induced mild and highly efficient aerial oxidation of aromatic aldehydes under solvent-free conditions, Catal. Commun., 2008, 9, 2588-2592.

23- T. G. Carrell, S. Cohen, G. C. Dismukes, Oxidative catalysis by $\mathrm{Mn}_{4} \mathrm{O}_{4}{ }^{6+}$ cubane complexes, J. Mol. Catal. A: Chem., 2002, 187, 3-15.

24- G. J. T. Brink, J. M. Vis, I.W.C. E. Arends, R. A. Sheldon, Selenium catalysed oxidations with aqueous hydrogen peroxide. Part 3:
Oxidation of carbonyl compounds under mono/bi/triphasic conditions, Tetrahedron, 2002, 58, 3977-3983.

25- S. Biella, L. Prati, M. Rossi, Gold-catalyzed the oxidation of aldehydes in the liquid phase, J. Mol. Catal. A: Chem., 2003, 197, 207-2012.

26- H. B. Ji, D. G. He, J. Song, Y. Qian, Clean Aerobic Liquid Oxidation of Aldehydes with Solid Catalyst, Chin. Chem. Lett., 2004, 15, 1241-1244.

27- I. El Amrani, A. Atlamsani, M. Dakkach, M. Rodríguez, I. Romero, S. Amthiou, Efficient and selective oxidation of aldehydes with dioxygen catalysed by vanadium-containing heteropolyanions, C. R. Chim., 2017, 20, 888895.

28- R. A. Sheldon, J. Dakka, Heterogeneous catalytic oxidations in the manufacture of fine chemicals, Catal. Today., 1994, 19, 215-245.

29- G. Centi, M. Misono, New possibilities and opportunities for basic and applied research on selective oxidation by solid catalysts: an overview, Catal. Today., 1998, 41, 287-296.

30- R. A. Sheldon, R. S. Downing, Heterogeneous catalytic transformations for environmentally friendly production, Appl. Catal., A, 1999, 189, 163-183.

31- J. S. Rafelt, J. H. Clark, Recent advances in the partial oxidation of organic molecules using heterogeneous catalysis, Catal. Today, 2000, 57, 33-44.

32- W. F. Hoelderich, Environmentally benign manufacturing of fine and intermediate chemicals, Catal. Today, 2000, 62, 115-130.

33- J. H. Clark, C. N. Rhodes, Clean Synthesis using Porous Inorganic Solid Catalysts and Supported Reagents, Royal Society of Chemistry, Cambridge, 2000.

34- S. Kanagasabapathy, A. Sudalai, B. C. Benicewicz, Montmorillonite K 10-catalyzed regioselective addition of thiols and thiobenzoic acids onto olefins: an efficient synthesis of dithiocarboxylic esters, Tetrahedron Lett., 2001, 42, 3791-3794.

35- D. Habibi, O. Marvi, Montmorillonite K-10 supported the one-pot synthesis of some symmetric diimides and 3a,4,7,7a-tetrahydro isoindole-1,3-dione derivatives under solventfree conditions using microwaves, J. Serb. Chem. Soc., 2005, 70, 579-583.

36- T. K. Huang, R. Wang, L. Shi, X. X. Lu, Montmorillonite K-10: An efficient and reusable catalyst for the synthesis of quinoxaline derivatives in water, Catal. Commun., 2008, 9, 1143-1147.

37- M. V. Reddy, G. C. S. Reddy, Y. T. Jeong, Microwave-assisted, montmorillonite K-10 catalyzed the three-component synthesis of $2 \mathrm{H}-$ indazolo[2,1-b]phthalazine-triones under solvent-free conditions, Tetrahedron, 2012, 68, 6820-6828 
38- T. R. Reddy, G. R. Reddy, L. S. Reddy, C. L.T. Meda, K.V. L. Parsa, K. S. Kumar, Y. Lingappa, M. Pal, Montmorillonite K-10 catalyzed the green synthesis of 2,6unsubstituted dihydropyridines as potential inhibitors of PDE4, Eur. J. Med. Chem., 2013, 62, 395-404.

39- T. Huang, R. Wang, L. Shi, X. Lu, Montmorillonite K-10: An efficient and reusable catalyst for the synthesis of quinoxaline derivatives in water, Catal. Commun., 2008, 9, 1143-1147.

40- M. D. Nikalje, P. Phukan, A. Sudalai, Recent advances clay-catalyzed organic transformations, Org. Prep. Proced. Int., 2000, 32, 1-40.

41- J. F. Roudier, A. Foucaud, Clay catalyzed enereactions. Synthesis of $\gamma$-lactones, Tetrahedron Lett., 1984, 25, 4375-4378.

42- S. Naskar, P. Paira, R. Paira, S. Mondal, A. Maity, A. Hazra, K. Sahu, P. Saha, S. Banerjee, P. Luger, M. Webe, N. Mondal, Montmorillonite K-10 clay catalyzed solventfree synthesis of bis-indolylindane1,3-dione,2(10,30-dihydro-1H-[2,30]biindolyl-20-ylidene)indan-1,3-dione and bisindolylindeno[1,2-b]quinoxaline under microwave irradiation, Tetrahedron, 2010, 66, 5196-5203.

43- O. Sieskind, P. Albrecht, Synthesis of alkylbenzenes by Friedel-Crafts reactions catalysed by K10-montmorillonite, Tetrahedron Lett., 1993, 34, 1197-1200.

44- D. Bahulayan, S. K. Das, J. Iqbal, Montmorillonite K10 Clay: An Efficient Catalyst for the One-Pot Stereoselective Synthesis of $\beta$-Acetamido Ketones, J. Org. Chem., 2003, 68, 5735-5738.

45- K. P. Naicker, A. Lalitha, K. Pitchumani, C. Srinivasan, Clay-catalysed dealkylation of organic sulfides, Catal. Lett., 1998, 56, 237239.

46- T. S. Li, J. X. Wang, X. J. Zheng, Simple synthesis of allobetulin, 28- oxvallobetulin and related biomarkers from betulin and betulinic acid catalysed by solid acids, J. Chem. Soc., Perkin Trans.1, 1998, 3957-3965.

47- V. A. Bushmelev, A. M. Genaev, V. G. Shubin, Oxidative demethylation of 4-methyl phenols to 1, 4-benzoquinones with hydrogen peroxide, catalyzed by K10 montmorillonite, Russ. J. Org. Chem., 1999, 30, 62-66.
48- H. Ohmura, G. D. Smyth, K. Mikami, The first example of $(2,5)$ ene cyclization: Solid acidcatalyzed oxonium-ene reaction, J. Org. Chem., 1999, 64, 6056-6059.

49- J. H. Poupaert, J. Bukuru, A. Gozzo, Clay (Montmorillonite K10) Catalysis of the Michael Addition of $\alpha, \beta$-Unsaturated Carbonyl Compounds to Indoles: The Beneficial Role of Alcohols, Monatsh. Chem., 1999, 130, 929-932.

50- N. S. Shaikh, A. S. Gajare, V. H. Deshpande, A.V. Bedekar, A mild procedure for the clay catalyzed selective removal of the tertbutoxycarbonyl protecting group from aromatic amines A mild procedure for the clay catalyzed selective removal of the tert-butoxycarbonyl protecting group from aromatic amines, Tetrahedron Lett., 2000, 41, 385-387.

51- M. Avalos, R. Babiano, J. L. Bravo, P. Cintas, J. L. Jiménez, J. C. Palacios, Clay-catalyzed solventless addition reactions of furan with $\alpha, \beta$-unsaturated carbonyl compounds, Tetrahedron Lett., 1998, 39, 9301-9304.

52- A. Bakandritsos, A. Simopoulos, D. Petridis, Iron Changes in Natural and Fe(III) Loaded Montmorillonite during Carbon Nanotube Growth, Nanotechnology, 2006, 17, 1112-1117.

53- P. Pushpaletha, S. Rugmini, M. Lalithambika, Correlation between surface properties and catalytic activity of clay catalysts, Appl. Clay Sci., 2005, 30, 141-153.

54- I. El Younssi, T. Rhadfi, A. Atlamsani, J-P, Quisefit, F. Herbst, K. Draoui, K-10 montmorillonite: An efficient and reusable catalyst for the aerobic CC bond cleavage of $\alpha$-substituted ketones, J. Mol. Catal. A: Chem., 2012; 363, 437-445.

55- R. Giannandrea, P. Mastrorilli, C. F. Nobile, G. P. Suranna, Aerobic oxidation of aldehydes, ketones, sulfides, alcohols and alkanes catalysed by polymerizable, $\beta$-ketoesterate complexes of iron(III), nickel(II) and cobalt(II), J. Mol. Catal., 1994, 94, 27-36.

56- C. Milone, M. Dhanagopal, S. Santangelo, M. Lanza, S. Galvagno, G. Messina, K10 Montmorillonite Based Catalysts for the Growth of Multiwalled Carbon Nanotubes through Catalytic Chemical Vapor Deposition, Eng. Chem. Res., 2010, 49, 3242-3249. 